\title{
Influence of light and nutrient conditions on seedling growth of native and invasive trees in the Seychelles
}

\author{
Journal Article \\ Author(s): \\ Schumacher, Eva; Kueffer, Christoph; Edwards, Peter J.; Dietz, Hansjörg \\ Publication date: \\ 2009 \\ Permanent link: \\ https://doi.org/10.3929/ethz-b-000019241 \\ Rights / license: \\ In Copyright - Non-Commercial Use Permitted \\ Originally published in: \\ Biological Invasions 11(8), https://doi.org/10.1007/s10530-008-9371-6
}




\title{
Influence of light and nutrient conditions on seedling growth of native and invasive trees in the Seychelles
}

\author{
Eva Schumacher $\cdot$ Christoph Kueffer • \\ Peter J. Edwards · Hansjörg Dietz
}

Received: 4 December 2007 / Accepted: 24 September 2008/Published online: 8 October 2008

(C) Springer Science+Business Media B.V. 2008

\begin{abstract}
Several recent studies have shown that plant invasions can occur in resource-poor and relatively undisturbed habitats. It is, therefore, important to investigate whether and how life-history traits of species invasive in such habitats differ from those of species that are only invasive in disturbed and resource rich habitats. We compared the growth of seedlings of native and invasive tree species from nutrient-poor secondary forests in the tropical Seychelles. We hypothesised that the relative performance of the two groups would change predictably along resource gradients, with native species performing better at low levels of resource availability and invasive species performing better at higher levels. To test this hypothesis, we performed a common garden experiment using seedlings of six invasive and seven native tree species grown under three levels of light $(65,11$ and $3.5 \%$ of ambient light) and two of nutrients (low and high). Due to large variation among species, differences in growth rates (RGR) were not significant among seedlings of the native and the invasive species. However, seedlings of the invasive species showed higher specific leaf areas (SLA) and higher leaf nutrient contents
\end{abstract}

E. Schumacher $(\bowtie) \cdot$ C. Kueffer · P. J. Edwards .

H. Dietz

Institute of Integrative Biology, Swiss Federal Institute

of Technology, Universitätsstrasse 18 ,

CH-8092 Zurich, Switzerland

e-mail: eva.schumacher@env.ethz.ch than seedlings of the native species. They also exhibited greater plasticity in biomass and nutrient allocation (i.e., greater plasticity in LAR, RSR and leaf nutrient contents) in response to varying resource availability. However, differences between the mean values of these parameters were generally small compared with variation within groups. We conclude that successful invaders on nutrient-poor soils in the Seychelles are either stress-tolerant, possessing growth traits similar to those of the native species, or fast-growing but adapted to nutrient-poor soils. In contrast, the more typical, fast-growing alien species with no particular adaptations to nutrient-poor soils seem to be restricted to relative nutrient-rich sites in the lowlands. The finding-that some introduced species thrive in resource-poor habitats-suggests that undisturbed habitats with low resource availability may be less resistant to plant invasions than was previously supposed.

Keywords Biomass allocation - Growth plasticity . Invasiveness · Resource-poor habitat .

Tropical tree seedlings

$\begin{array}{ll}\text { Abbreviation list } \\ \text { HR } & \text { High radiation } \\ \text { IR } & \text { Intermediate radiation } \\ \text { LR } & \text { Low radiation } \\ \text { HN } & \text { High nutrient availability } \\ \text { LN } & \text { Low nutrient availability } \\ \text { RGR }_{\text {Dw }} & \text { Relative growth rate of total dry weight }\end{array}$




$\begin{array}{ll}\text { RGR }_{\text {LA }} & \text { Relative growth rate of leaf area } \\ \text { Root }_{\text {DW }} & \text { Root dry weight } \\ \text { SLA } & \text { Specific leaf area } \\ \text { LAR } & \text { Leaf area ratio } \\ \text { RSR } & \text { Root:shoot ratio } \\ \text { N } & \text { Nitrogen } \\ \text { P } & \text { Phosphorus }\end{array}$

\section{Introduction}

Although only a small fraction of introduced species become invasive (Williamson 1996), some of these can cause enormous ecological and economic damage (Millennium Ecosystem Assessment 2005; Pimentel et al. 2005). Much research has therefore been devoted to understanding which traits make some species more invasive than others (invasiveness, Kolar and Lodge 2001; Grotkopp et al. 2002; Daehler 2003).

Plant traits frequently associated with invasiveness include high specific leaf area (SLA, Baruch and Goldstein 1999; Daehler 2003; Richardson and Pysek 2006) and high leaf nitrogen content (Dukes and Mooney 1999; Ehrenfeld 2003; Niinemets et al. 2003), and both of these help to explain why invasive plants tend to grow fast under high resource conditions (for tropical woody invaders, e.g., Baruch et al. 2000). In a comparative study of 29 Pinus species, for example, the most important predictor of invasiveness was found to be relative growth rate (RGR) of seedlings; and the main trait responsible for differences in RGR between native and invasive species was SLA (Grotkopp et al. 2002). In addition, invaders often show higher phenotypic plasticity than native species (Daehler 2003; Richardson and Pysek 2006; and references therein).

Despite these trends, however, it is still not possible to generalise about what makes some species invasive (Kolar and Lodge 2001; Daehler 2003). One reason for this may be that the traits associated with invasiveness vary according to both habitat conditions and the stage of the invasion (Alpert et al. 2000; Dietz and Edwards 2006). Daehler (2003) found that alien invaders were not always competitively superior to native species, but rather that the competitive hierarchy between native and alien species shifted according to both resource availability and disturbance regime. On the basis of such observations, Richards et al. (2006) proposed a scheme for classifying invaders based on their performance relative to co-occurring native species under resource-poor and favourable conditions. According to this scheme, an invader that outperforms native species under resource-poor conditions is a 'jack-of-all-trades', while one that succeeds only under favourable conditions is a 'master-ofsome'; and a species that succeeds under both conditions is a 'jack-and-master'.

Given that the invasiveness of individual species may depend upon resource availability in the new habitat, it is desirable to study invasions under a wide range of conditions. Most research on invasive plants, however, has been conducted in disturbed, resourcerich habitats (primary invasion sensu Dietz and Edwards 2006), simply because alien plants tend to be most abundant in such habitats (compare Alpert et al. 2000; Davis et al. 2000). Thus, the traits commonly associated with successful invaders, such as high SLA or RGR, could be interpreted as those characteristic of plants adapted to these environmental conditions (in tropical trees see e.g., Veneklaas and Poorter 1998). However, invasions also occur in resource-poor and/or relatively undisturbed habitats, as has become evident from an increasing number of studies (e.g., Stohlgren et al. 1999; Burke 2003; Cavieres et al. 2005; Martin and Marks 2006). For example, some tropical forests on oceanic islands are heavily invaded (Denslow 2003), even though their soils are very nutrient poor (Vitousek 2004; Kueffer 2006). Further, plant invasions on oceanic islands sometimes occur in closed vegetation (e.g., Huenneke and Vitousek 1990; Vitousek 1990; Fleischmann 1997), while invasions in continental tropical forests have often been attributed to higher light levels resulting from disturbance (Fine 2002).

The granitic island of Mahé (Republic of Seychelles) offers a wide diversity of terrestrial habitats, all of which have been invaded to some extent by alien species. These habitats range from relatively nutrient-rich, open vegetation in the lowlands to very nutrient-poor, closed secondary forest in the uplands. However, despite the high environmental heterogeneity, the total number of woody species on Mahé is rather small, with around 20 abundant native species and even fewer invasive species. As a consequence, many species occur across a broad ecological range, with the same set of invasive and native species growing under both resource-rich and resource-poor conditions. 
Based on a large body of evidence derived mainly from disturbed and nutrient-rich habitats (e.g. Daehler 2003), we hypothesised that the relative performance of native and invasive woody plant species would change predictably along resource gradients in the Seychelles, with native species outperforming invasive species under conditions of low light and low nutrients but with invasive species being better able to exploit higher levels of these resources. To test this hypothesis, we performed an experiment to investigate the growth of seedlings of six invasive and seven native species under a range of light and nutrient conditions.

\section{Materials and methods}

General study area $\left(4^{\circ} \mathrm{S}, 55^{\circ} \mathrm{E}, 154 \mathrm{~km}^{2}, 0-900 \mathrm{~m}\right.$ asl). It is composed of granite 550-650 Mio years old that has never been weathering (Braithwaite 1984), the soils-which are typically ferrasols with a $\mathrm{pH}$ of c. 4.5-are poor in most nutrients, especially phosphorus (cf. Kueffer 2006). garden experiment. The three different experimental runs S1,
Mahé is the largest island in the inner Seychelles group covered by the ocean. As a result of a long history of

Table 1 Characterization of the species used in the common S2 and S3 were started on 27 Oct 2002 (duration 201-

Inland forests in Seychelles are characterized by a humid tropical climate, with a mean annual rainfall of between 1600 and $3500 \mathrm{~mm}$ depending on altitude (Stoddart 1984). Although there is no pronounced seasonality in precipitation, the period from May to October is generally drier than the rest of the year. Monthly mean temperatures range from 26 to $28^{\circ} \mathrm{C}$ (Meteo Seychelles). In most inland forests the invasive tree Cinnamomum verum dominates the canopy.

No native forest remains in the lowlands of Mahé but there are extensive areas of secondary forest, much of it dominated by the invasive tree $C$. verum (Kueffer et al. 2007). In contrast, the montane mist forests retain a higher proportion of native species, though even these are heavily invaded.

\section{Species}

We selected six invasive and seven native tree species, all of them common in the non-coastal secondary forests of the inner islands of the Seychelles (Table 1). In selecting the species, we avoided having closely related species within the same group, and also excluded N-fixing trees (e.g., the introduced Falcataria moluccana). The native

226 days), 3 Jun 2003 (duration 180 days) and 6 Dec 2003 (duration 210 days), respectively. Nomenclature and maximal stem height was taken from Friedmann (1994)

\begin{tabular}{|c|c|c|c|}
\hline Species & Family & Maximal stem height (m) & Experimental run \\
\hline \multicolumn{4}{|l|}{ Invasives } \\
\hline Alstonia macrophylla & Apocynaceae & 15 & $\mathrm{~S} 2$ \\
\hline Cinnamomum verum & Lauraceae & 15 & $\mathrm{~S} 2$ \\
\hline Psidium cattleianum & Myrtaceae & 7 & $\mathrm{~S} 1$ \\
\hline Sandoricum koetjape & Meliaceae & 25 & $\mathrm{~S} 2$ \\
\hline Syzygium jambos & Myrtaceae & 10 & $\mathrm{~S} 2$ \\
\hline Tabebuia pallida & Bigogniaceae & 10 & $\mathrm{~S} 1$ \\
\hline \multicolumn{4}{|l|}{ Natives } \\
\hline Aphloia theiformis ${ }^{\mathrm{a}}$ & Flacourtiaceae & 12 & $\mathrm{~S} 3$ \\
\hline Canthium bibracteatum & Rubiaceae & 8 & $\mathrm{~S} 3$ \\
\hline Erythroxylum sechellarum ${ }^{\mathrm{b}}$ & Erythroxylaceae & 7 & $\mathrm{~S} 1$ \\
\hline Memecylon eleagni ${ }^{\mathrm{b}}$ & Melastomataceae & 10 & S3 \\
\hline Paragenipa wrightii $^{\mathrm{b}}$ & Rubiaceae & 6 & $\mathrm{~S} 1$ \\
\hline Psychotria pervillei ${ }^{\mathrm{b}}$ & Rubiaceae & 4 & S3 \\
\hline Syzygium wrightii ${ }^{b}$ & Myrtaceae & 20 & $\mathrm{~S} 1$ \\
\hline
\end{tabular}


species included two indigenous and five endemic species. The majority of the invasive species were introduced to the islands in the late 19th or early 20th century, but C. verum and Syzygium jambos have been present for more than 200 years (Kueffer and Vos 2004). Most species had seeds in the range of 2 to $10 \mathrm{~mm}$ diameter, but two invasive species, Sandoricum koetjape and $S$. jambos, had larger seeds (15-20 mm). Nomenclature follows Friedmann (1994).

\section{Common garden experiment}

The experiment was conducted on a flat, unshaded lawn on the eastern slope of Morne Seychellois at the Sans Souci forestry station $\left(4^{\circ} 38^{\prime} \mathrm{S}\right.$ and $55^{\circ} 27^{\prime} \mathrm{E}$; $380 \mathrm{~m}$ asl., Fig. 1a).

For each species, seed was collected from 5 to 15 trees growing in the forest, and sown immediately into trays. When the seedlings had developed their first true leaves (3-6 months after sowing), c. 50 plants per species were randomly selected and transplanted into 1-1 pots filled with local forest soil (see below). Because no seed of Alstonia macrophylla could be obtained, seedlings similar in size to those of the other species were collected from several forest sites on Mahé. All plants were allowed to adjust to the pot environment for 2 weeks before the experiments were started. At the onset of the experiment 36 plants per species were randomly selected and distributed among experimental treatments, while the other individuals were used for initial measurements (see below).

We chose three levels of irradiance to represent typical light conditions within the forests: $65 \%$ ambient light for gap conditions (c. 1,000 $\mu \mathrm{mol} \mathrm{m} \mathrm{m}^{-2} \mathrm{~s}^{-1}$ photosynthetically active radiation (PAR) on a sunny day, high radiation, HR), $11 \%$ ambient light for disturbed understorey (c. $175 \mu \mathrm{mol} \mathrm{m} \mathrm{m}^{-2} \mathrm{~s}^{-1}$ PAR, intermediate radiation, IR), and 3.5\% ambient light for closed native forest (c. $50 \mu \mathrm{mol} \mathrm{m} \mathrm{m}^{-2} \mathrm{~s}^{-1}$ PAR, low radiation, LR). These light conditions were achieved by constructing wooden frames with sloping roofs (height $1-1.4 \mathrm{~m}$; area $1.6 \mathrm{~m} \times 1.8 \mathrm{~m}$; Fig. $1 \mathrm{~b}$ ) and covering them with green shading cloths with the appropriate transmittance (Agroflor, Austria). These a

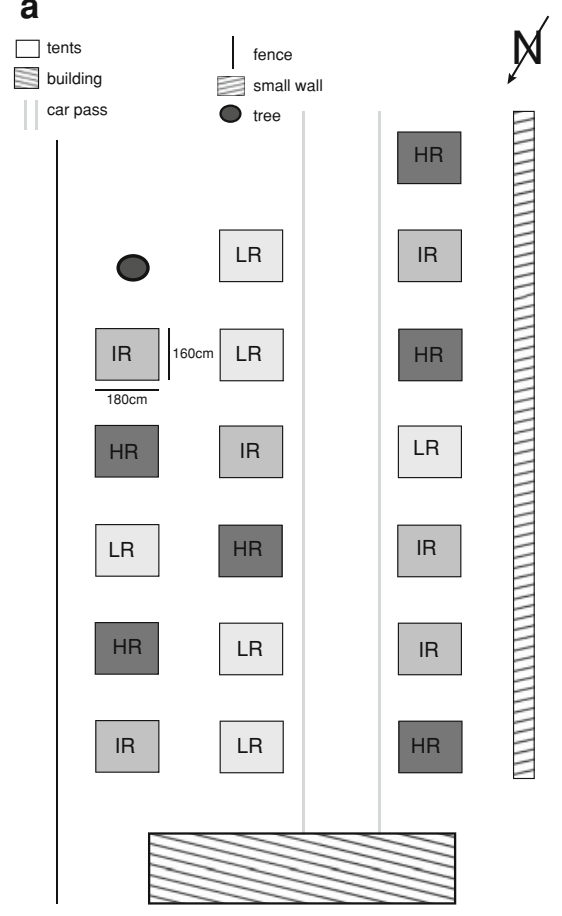

Fig. 1 a Schematic view of the arrangement of shading tents used in the common garden experiment at Sans Souci forestry station: HR (high light), IR (intermediate light), LR (low light). b
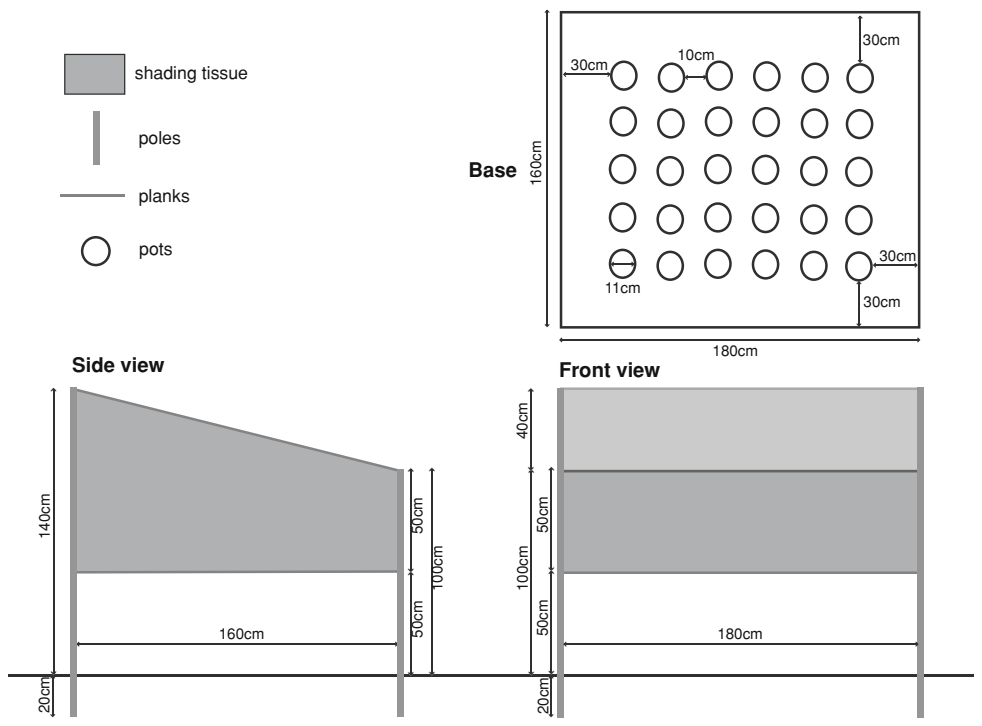

In total 468 plants were used in the experiment. b Design of the shading tents and the arrangement of pots within them. See text for further information 
'tents' were calibrated using a PAR-sensor to determine the light level inside as a percentage of that outside of the tent. To prevent humidity and temperature in the tents rising above the ambient levels, there was no shading cloth around the bottom $50 \mathrm{~cm}$ of the frame. In practice, temperatures tended to be somewhat higher $\left(36^{\circ} \mathrm{C}\right.$ vs. $\left.32^{\circ} \mathrm{C}\right)$ and relative humidities lower (60\% vs. $75 \%)$ under HR compared to IR and LR (measurements made around noon on sunny days). Two nutrient levels were chosen to represent typical conditions of low (LN) and high nutrient (HN) availability in forest soils on Mahé. For the $\mathrm{LN}$ treatment we mixed organic forest topsoil with laterite soil (35\% organic soil, $65 \%$ laterite soil, vol\%), resulting in soil that was poorer in nutrients than most forest soils in the Seychelles (Kjedahl N $1.5 \mathrm{mg} \mathrm{g}^{-1}$; P $0.4 \mathrm{mg} \mathrm{g}^{-1}$ ). For the $\mathrm{HN}$ treatment the same mixture was used but $1 \mathrm{~g}$ of a slow release N-P-K-fertilizer (Osmocote 16:11:11, Osmocote, Scotland) was applied to each pot every 2 months.

The tents were arranged in a block design with six replicates per light treatment (Fig. 1a). A split-plot design was used with light as the main-plot factor and nutrients as the split-plot factor. In each tent there were two plants per species, one for each nutrient treatment. Aphloia theiformis was not included in the low-light treatment because of a shortage of seedlings. The plants were redistributed monthly within the tents to avoid local position effects. Due to the varying availability of seeds and seedlings of the different species, the experiment was conducted in three series starting in October 2002, June 2003 and December 2003. Each series lasted for 6-7 months (Table 1).

\section{Data collection}

At the onset of each series, four to six randomly chosen seedlings of each species were harvested to determine the initial total dry weight. Thereafter, the following parameters were measured on all plants at 1-2-month intervals: stem height, number of leaves, leaf length and breadth, and stem diameter (using callipers).

To estimate leaf area, linear regressions of leaf area on the product of leaf length and width were calculated for a sample of $>100$ leaves per species from seedlings of different sizes collected in the field. The sample leaves were placed beneath a glass plate and photographed with a digital camera (Nikon Coolpix 995, resolution at $2048 \times 1536$ pixels). The images were used to determine leaf length and width using Adobe Illustrator $^{\mathrm{TM}} 10$, and leaf area using Adobe Photoshop $^{\text {TM }} 7.0$ (cf. Dietz and Steinlein 1996).

At the end of the experiment, plants were harvested and divided into leaves, stems plus petioles, and roots. All material was oven-dried at $80^{\circ} \mathrm{C}$ for $48 \mathrm{~h}$. Subsamples of the leaf material were digested at $420^{\circ} \mathrm{C}$ with $98 \% \mathrm{H}_{2} \mathrm{SO}_{4}$ and Merck Kjeltabs. Total nitrogen and phosphorus concentrations of leaves were determined colorimetrically using a flow injection analyzer (FIA, TECATOR, Höganäs, Sweden).

The raw data were used to calculate the following growth parameters (Gibson 2002):

\begin{tabular}{|c|c|c|}
\hline RGR $_{\text {DW }}$ & $\begin{array}{l}\text { Relative } \\
\text { growth rate } \\
\text { by dry } \\
\text { weight }\end{array}$ & $\begin{array}{l}\ln (\text { dry weight at end) } \\
\ln (\text { dry weight at start) } \\
\text { duration of experiment }\end{array}$ \\
\hline $\mathbf{R G R}_{\mathbf{L A}}$ & $\begin{array}{l}\text { Relative } \\
\text { growth rate } \\
\text { by leaf area }\end{array}$ & $\begin{array}{l}\ln (\text { leaf area at end) } \\
\frac{\ln (\text { leaf area at start }}{\text { duration of experiment }}\end{array}$ \\
\hline SLA & $\begin{array}{l}\text { Specific leaf } \\
\text { area }\end{array}$ & $\frac{\text { leaf area }}{\text { dry leaf biomass }}$ \\
\hline LAR & $\begin{array}{l}\text { Leaf area } \\
\quad \text { ratio }\end{array}$ & $\frac{\text { leaf area }}{\text { dry plant biomass }}$ \\
\hline RSR & $\begin{array}{l}\text { Root:shoot } \\
\text { ratio }\end{array}$ & $\frac{\text { dry root biomass }}{\text { dry shoot biomass }}$ \\
\hline
\end{tabular}

Data analysis

There was considerable variation in the initial biomass of seedlings, both between invasive and native species (compare also Schmitt and Riviere 2002) and between small- and larger-seeded species, of similar-aged individuals. To control for any influence on the results of size variation at the start of the experiment, we analysed not only relative growth rates (i.e. exponential growth) but also linear growth (i.e. (biomass End biomass $\left._{\text {Start }}\right) /$ time) and total biomass at the end of the experiment. However, we found no qualitative differences in the results from the two approaches.

Due to the death of many seedlings in the low light/ high nutrient treatment, we performed two separate analyses of the data. In the first analysis, only the data for the low nutrient treatment were analysed. General linear models were used with light level, species status (native or invasive) and the corresponding interaction as fixed factors, and species identity (nested in species status) and shading tents (nested in light treatments) as 
random factors. To account for initial differences in size, leaf area of each plant at the start of the experiment was included as a covariable. The second analysis included plants growing at intermediate and high light levels and both fertilized and unfertilized pots. A similar statistical model was used, but with nutrient level and corresponding interactions as additional fixed factors. Plant growth (relative growth rate of total dry weight and leaf area), changes in plant morphology or allocation (SLA, LAR, RSR) and leaf nutrient content (nitrogen $\mathrm{N}$ and phosphorus $\mathrm{P}$ and $\mathrm{N}: \mathrm{P}$ ratio) were included as dependent variables. To remove heteroscedasticity, SLA, LAR and RSR were log-transformed, while $\mathrm{N}$ and $\mathrm{P}$ contents were squareroot transformed prior to analysis. In the case of the leaf parameters some outliers were excluded. Syzygium wrightii was excluded from all analyses due to very high mortality in most treatments, and Aphloia theiformis was omitted from the first analysis because there was no low light treatment. All statistical analyses were performed with JMP V 6.0 (SAS Institute Inc., 2005).

\section{Results}

Under most treatments mortality among the seedlings was relatively low, ranging from 0 to $26 \%$ according to species and treatment, and with an overall mean value of $10 \%$. However, seedlings subjected to both low light (LR) and high nutrients (HN) had a much higher average mortality of $48 \%$. There were no consistent differences in mortality between native and invasive species.

Responses of the species to variation in light and nutrient availability

\section{Relative growth rate}

The seedlings of both native and invasive species usually developed more biomass (relative growth rate of total dry weight, $\mathrm{RGR}_{\mathrm{DW}}$ ) under higher light conditions (Fig. 2a, Table 2), and the magnitude of the response was similar for both species groups (species status $\times$ light interaction, Table 2). Mean $\mathrm{RGR}_{\mathrm{DW}}$ of native species was about $50 \%$ lower than that of invasive species under low light and $15 \%$ lower under intermediate and high light, but neither of these differences was significant because of high within-group variation (Fig. 2a). Thus among invasive species $\mathrm{RGR}_{\mathrm{DW}}$ ranged from 0.3 to $11.0 \mathrm{mg} \mathrm{g}^{-1} \mathrm{~d}^{-1}$ under low light and from 6.2 to $20.6 \mathrm{mg} \mathrm{g}^{-1} \mathrm{~d}^{-1}$ under high light, while among native species it ranged from 0.7 to $6.9 \mathrm{mg} \mathrm{g}^{-1} \mathrm{~d}^{-1}$ under low light and from 2.5 to $21.4 \mathrm{mg} \mathrm{g}^{-1} \mathrm{~d}^{-1}$ under high light. Overall, status explained only $1.5 \%$ of the variation in $\mathrm{RGR}_{\mathrm{DW}}$ (one-way ANOVA).

At intermediate (IR) and high light levels (HR), the seedlings of both native and invasive species had a

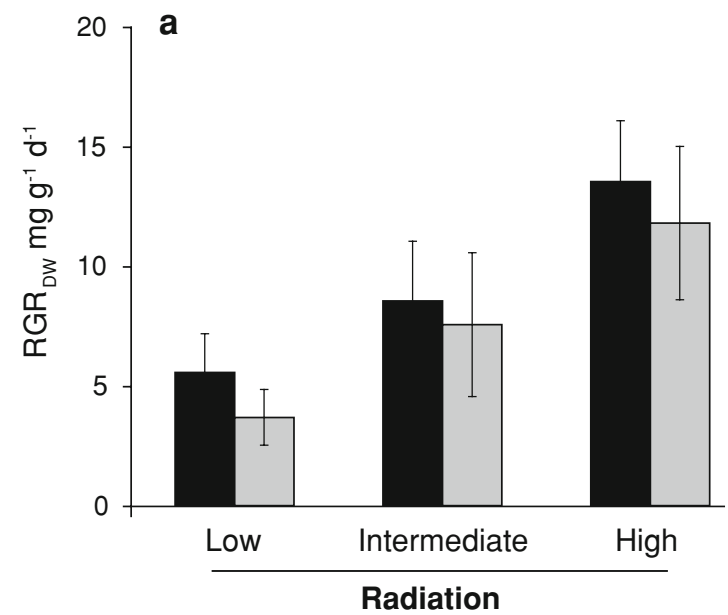

Fig. 2 RGR $_{\mathrm{DW}}$ of invasive (black bars) and native (grey bars) species (mean $\pm \mathrm{SE}$, based on species means). a Plants growing under three light levels with no fertilizer added. b

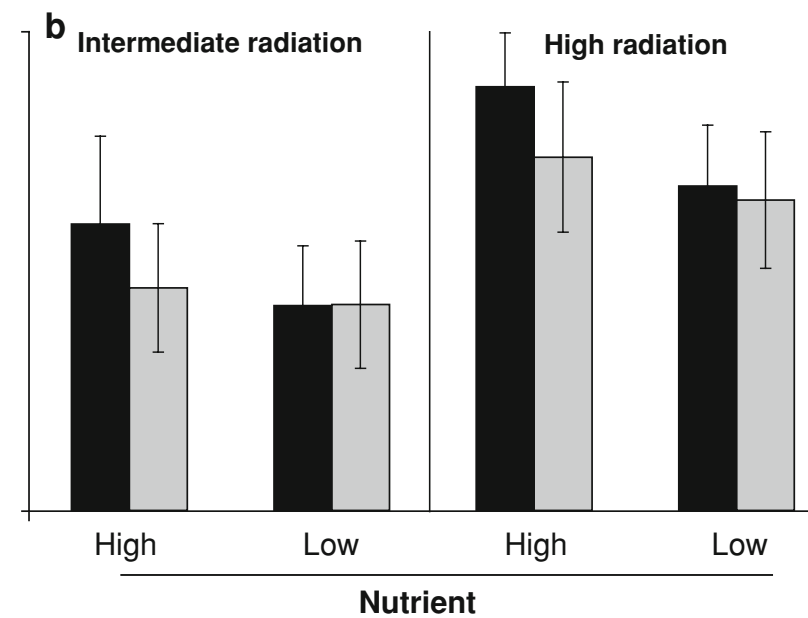

Plants growing under two light levels and two nutrient levels. See text for further information 
Table 2 Results of ANOVA across all three light levels at low nutrient availability

\begin{tabular}{|c|c|c|c|c|c|c|c|c|c|c|c|c|c|c|}
\hline & \multicolumn{3}{|l|}{$\mathbf{R G R}_{\mathbf{D W}}$} & \multicolumn{4}{|l|}{ SLA } & \multicolumn{3}{|l|}{ LAR } & \multicolumn{4}{|l|}{ RSR } \\
\hline & SS & d.f. & $\mathrm{F}, \mathrm{P}$ & SS & d.f & $\mathrm{F}, \mathrm{P}$ & & SS & d.f. & $\mathrm{F}, \mathrm{P}$ & SS & & d.f. & $\mathrm{F}, \mathrm{P}$ \\
\hline \multicolumn{15}{|l|}{ (a) } \\
\hline Species group $^{\mathrm{a}}(\mathrm{S})$ & $3.0 \times 10^{-5}$ & 1 & 0.33 & 1.02 & 1 & \multicolumn{2}{|c|}{2.63} & 0.90 & 1 & 2.71 & \multicolumn{2}{|c|}{$3.9 \times 10^{-3}$} & 1 & 0.02 \\
\hline Light (L) & $1.4 \times 10^{-3}$ & 2 & $13.39 * * *$ & 9.98 & 2 & \multicolumn{2}{|c|}{$41.38 * * *$} & 16.24 & 2 & $45.80 * * *$ & \multicolumn{2}{|l|}{7.17} & 2 & $14.29 * * *$ \\
\hline $\mathrm{S} \times \mathrm{L}$ & $6.5 \times 10^{-6}$ & 2 & 0.06 & 0.08 & 2 & \multicolumn{2}{|c|}{0.33} & 1.12 & 2 & $3.75^{*}$ & \multicolumn{2}{|l|}{2.66} & 2 & $6.81 * *$ \\
\hline Initial leaf area & $1.7 \times 10^{-6}$ & 1 & 0.26 & $9.5 \times 10^{-3}$ & 1 & \multicolumn{2}{|c|}{0.47} & 0.05 & 1 & 0.99 & \multicolumn{2}{|c|}{$4.0 \times 10^{-3}$} & 1 & 0.04 \\
\hline \multirow[t]{3}{*}{ Residuals } & $7.1 \times 10^{-4}$ & 106 & & 2.08 & 103 & & & 5.01 & 102 & & 9.98 & & 106 & \\
\hline & \multicolumn{3}{|l|}{$\mathbf{N}: \mathbf{P}$} & \multicolumn{5}{|l|}{$\mathbf{N}$} & \multicolumn{4}{|l|}{$\mathbf{P}$} & & \\
\hline & SS & d.f. & $\mathrm{F}, \mathrm{P}$ & SS & & d.f & $\mathrm{F}, \mathrm{P}$ & & SS & & d.f. & $\mathrm{F}, \mathrm{P}$ & & \\
\hline \multicolumn{15}{|l|}{ (b) } \\
\hline Species group $^{\mathrm{a}}(\mathrm{S})$ & 5.25 & 1 & 0.16 & 4.07 & & 1 & \multicolumn{2}{|l|}{3.76} & \multicolumn{2}{|c|}{0.17} & 1 & \multicolumn{2}{|c|}{$4.78 *$} & \\
\hline Light (L) & 469.04 & 2 & $5.63 * *$ & 15.87 & & 2 & \multicolumn{2}{|c|}{$10.29 * * *$} & \multicolumn{2}{|c|}{0.11} & 2 & \multicolumn{2}{|c|}{$4.82 *$} & \\
\hline $\mathrm{S} \times \mathrm{L}$ & 124.60 & 2 & 1.35 & 1.77 & & 2 & \multicolumn{2}{|l|}{1.12} & \multicolumn{2}{|l|}{0.01} & 2 & \multicolumn{2}{|l|}{0.41} & \\
\hline Initial leaf area & 5.46 & 1 & 0.57 & $3.4 \times 10^{-4}$ & & 1 & \multicolumn{2}{|c|}{0.003} & \multicolumn{2}{|c|}{$7.6 \times 10^{-3}$} & 1 & \multicolumn{2}{|l|}{1.38} & \\
\hline Residuals & 797.70 & 83 & & 10.43 & & 85 & & & 0.46 & & 84 & & & \\
\hline
\end{tabular}

Indicated are the sum of squares (SS), degrees of freedom (d.f.), $F$-ratios and significance levels $(* * * P<0.001, * * P<0.01$, * $P<0.05$, significant ones in bold) of main effects and interactions for the following parameters: 2a. relative growth rate of dry weight $\left(\mathrm{RGR}_{\mathrm{DW}}\right)$, specific leaf area (SLA), leaf area ratio (LAR), root:shoot ratio (RSR); 2b. nitrogen to phosphorus ratio (N:P), $\mathrm{N} \& \mathrm{P}$ concentrations in leaves. (Statistics are not shown for random factors)

${ }^{\text {a }}$ Native vs. invasive

higher $\mathrm{RGR}_{\mathrm{DW}}$ in the fertilized pots $(\mathrm{HN})$ than in the unfertilized pots (LN; Fig. 2b, Table 3). This effect did not differ between light treatments (light $\times$ nutrient, Table 3), but invasive species responded more strongly to added nutrients than natives (species group $\times$ nutrient, Table 3). Again, the mean growth rates of the invasive species were not consistently and significantly higher than those of the native species (Fig. 2b, Table 3), partly because of the large variation within species groups. With the addition of nutrients, several species were able to almost double their growth rate. These included the native Memecylon eleagni and the invasive S. koetjape under IR, and the native Paragenipa wrightii and the invasive $S$. jambos under HR. In contrast, nutrient addition reduced the $\mathrm{RGR}_{\mathrm{DW}}$ of several species including the native $P$. wrightii and the invasive Tabebuia pallida under IR, and the native Psychotria pervillei under HR.

The relative growth rates of height $\left(\mathrm{RGR}_{\mathrm{H}}\right)$ and total leaf area $\left(\mathrm{RGR}_{\mathrm{LA}}\right)$ were both significantly correlated with $\mathrm{RGR}_{\mathrm{DW}}(r>0.5, P<0.01)$ and the data are therefore not shown.

\section{Biomass allocation}

Specific leaf area (SLA) and leaf area ratio (LAR) were strongly affected by light conditions and also varied widely among species. For instance, the SLA of the invasive A. macrophylla under low light was about three-times higher than under high light $\left(550 \mathrm{~cm}^{2} \mathrm{~g}^{-1}\right.$ vs. $170 \mathrm{~cm}^{2} \mathrm{~g}^{-1}$ ). In contrast, light conditions had a much smaller effect on the SLA of another invasive species, S. jambos, and values were always much lower than those of A. macrophylla (LR $120 \mathrm{~cm}^{2} \mathrm{~g}^{-1}$, HR $\left.95 \mathrm{~cm}^{2} \mathrm{~g}^{-1}\right)$. Among the native species, the highest values of SLA were found in $P$. pervillei (c. $290 \mathrm{~cm}^{2} \mathrm{~g}^{-1}$ vs. c. $120 \mathrm{~cm}^{2} \mathrm{~g}^{-1}$ ) and the lowest in M. eleagni (c. $110 \mathrm{~cm}^{2} \mathrm{~g}^{-1}$ vs. c. $75 \mathrm{~cm}^{2} \mathrm{~g}^{-1}$ ).

In both species groups, mean SLA (Fig. 3) and LAR (data not shown) decreased strongly with increasing light availability (Table 2), but there were no clear responses of these parameters to nutrient addition (Table 2). Mean values of SLA and LAR were about $50 \%$ higher in the invasive than in the native species, with both differences being significant 
Table 3 Results of ANOVA across two light and two nutrient levels

\begin{tabular}{|c|c|c|c|c|c|c|c|c|c|c|c|c|}
\hline & \multicolumn{3}{|l|}{$\mathrm{RGR}_{\mathrm{DW}}$} & \multicolumn{3}{|l|}{ SLA } & \multicolumn{3}{|l|}{ LAR } & \multicolumn{3}{|l|}{ RSR } \\
\hline & SS & d.f. & $\mathrm{F}, \mathrm{P}$ & SS & d.f & $\mathrm{F}, \mathrm{P}$ & SS & d.f. & $\mathrm{F}, \mathrm{P}$ & SS & d.f. & $\mathrm{F}, \mathrm{P}$ \\
\hline \multicolumn{13}{|l|}{ (a) } \\
\hline Species group $^{a}(\mathrm{~S})$ & $4.5 \times 10^{-5}$ & 1 & 0.26 & 1.69 & 1 & $4.96 *$ & 0.99 & 1 & $4.92 *$ & 0.09 & 1 & 0.35 \\
\hline Light (L) & $1.6 \times 10^{-3}$ & 1 & $10.86 * *$ & 13.39 & 1 & 63.02**** & 19.19 & 1 & $63.38 * * *$ & 7.85 & 1 & $29.18 * * *$ \\
\hline $\mathrm{S} \times \mathrm{L}$ & $1.0 \times 10^{-5}$ & 1 & 0.07 & 0.09 & 1 & 0.46 & 0.74 & 1 & 3.08 & 1.80 & 1 & $7.94 *$ \\
\hline Nutrient $(\mathrm{N})$ & $3.7 \times 10^{-4}$ & 1 & $26.41 * * *$ & 0.12 & 1 & 2.55 & 0.02 & 1 & 0.34 & 1.64 & 1 & $7.37 *$ \\
\hline $\mathrm{S} \times \mathrm{N}$ & $8.7 \times 10^{-5}$ & 1 & $6.21 *$ & 0.01 & 1 & 0.24 & 0.27 & 1 & 4.41 & 0.87 & 1 & 3.92 \\
\hline $\mathrm{L} \times \mathrm{N}$ & $1.2 \times 10^{-5}$ & 1 & 1.86 & 0.03 & 1 & 1.55 & 0.17 & 1 & $4.56^{*}$ & 0.31 & 1 & 3.66 \\
\hline Initial leaf area & $5.5 \times 10^{-6}$ & 1 & 0.86 & 0.02 & 1 & 1.28 & 0.05 & 1 & 1.38 & 0.01 & 1 & 0.07 \\
\hline \multirow[t]{3}{*}{ Residuals } & $1.2 \times 10^{-3}$ & 189 & & 3.29 & 186 & & 6.74 & 180 & & 15.94 & 188 & \\
\hline & \multicolumn{3}{|l|}{$\mathbf{N}: \mathbf{P}$} & \multicolumn{3}{|l|}{$\mathbf{N}$} & \multicolumn{4}{|l|}{$\mathbf{P}$} & & \\
\hline & SS & d.f. & $\mathrm{F}, \mathrm{P}$ & SS & d.f & $\mathrm{F}, \mathrm{P}$ & SS & & d.f. & $\mathrm{F}, \mathrm{P}$ & & \\
\hline \multicolumn{13}{|l|}{ (b) } \\
\hline Species group $^{a}(\mathrm{~S})$ & 8.30 & 1 & 0.18 & 6.31 & 1 & $6.79 *$ & \multicolumn{2}{|c|}{0.52} & 1 & \multicolumn{2}{|l|}{$12.47 * *$} & \\
\hline Light (L) & 693.30 & 1 & $18.50^{* *}$ & 11.35 & 1 & $10.22 * *$ & \multicolumn{2}{|c|}{$1.0 \times 10^{-6}$} & 1 & 0.00 & & \\
\hline $\mathrm{S} \times \mathrm{L}$ & 2.37 & 1 & 0.06 & 0.32 & 1 & 0.27 & 0.04 & & 1 & 1.87 & & \\
\hline Nutrient (N) & 305.60 & 1 & $17.88 * *$ & 16.64 & 1 & $59.82 * * *$ & 0.23 & & 1 & $28.56 * *$ & & \\
\hline $\mathrm{S} \times \mathrm{N}$ & 0.21 & 1 & 0.01 & 2.31 & 1 & $8.4 * *$ & 0.13 & & 1 & $16.82 * *$ & & \\
\hline $\mathrm{L} \times \mathrm{N}$ & 5.06 & 1 & 0.81 & 1.42 & 1 & $11.40 * * *$ & 0.15 & & 1 & $26.88 * *$ & & \\
\hline Initial leaf area & 3.83 & 1 & 0.62 & 0.01 & 1 & 0.09 & 0.01 & & 1 & 1.00 & & \\
\hline Residuals & 955.58 & 154 & & 19.75 & 159 & & 0.87 & & 160 & & & \\
\hline
\end{tabular}

Indicated are the sum of squares (SS), degrees of freedom (d.f.), $F$-ratios and significance levels $(* * * P<0.001, * * P<0.01$, $* P<0.05$, significant ones in bold) of main effects and interactions for the following parameters: $2 \mathrm{a}$. RGR $\mathrm{DW}_{\mathrm{DW}}, \mathrm{SLA}, \mathrm{LAR}, \mathrm{RSR} ; 2 \mathrm{~b}$. $\mathrm{N}: \mathrm{P}, \mathrm{N}, \mathrm{P}$. Statistics are not shown for random factors and three-way interactions. See Table 2 for acronyms

a Native vs. invasive

(across two light and nutrient levels; Table 3). In addition, the invasive species showed a relatively higher LAR than the native species under LR and IR than under HR (significant species status $\times$ light availability interaction, Table 2).

The root:shoot ratios (RSR, Table 2, Fig. 4) varied widely, from 0.2 under IR-HN to 0.9 under HR-LN. In all species, RSR was higher under HR than IR, and was lower in fertilized pots. Overall, the RSR of invasive species responded more strongly to light addition than did that of the native species (interaction effects of species status with light, Tables 2 and 3, Fig. 4).

\section{Leaf nutrient contents}

In the low nutrient treatments, leaf nitrogen $(\mathrm{N})$ and phosphorus (P) concentrations decreased with increasing light (Table 2, Fig. 5), particularly between $\mathrm{IR}$ and HR. Among the invasive species, mean N concentrations ranged from $24 \mathrm{mg} \mathrm{g}^{-1}$ under LR to $13 \mathrm{mg} \mathrm{g}^{-1}$ under HR, while the corresponding range for $\mathrm{P}$ was from $1.2 \mathrm{mg} \mathrm{g}^{-1}$ to $1.0 \mathrm{mg} \mathrm{g}^{-1}$. Under all light levels, $\mathrm{N}$ and $\mathrm{P}$ concentrations were $20-50 \%$ higher in the invasive than native species (Table 2). The difference in $\mathrm{N}$ content between species groups was most pronounced under LR, resulting in an N:P ratio that was about $30 \%$ higher for invasive (21) than for native species (16). In contrast, the N:P ratios did not differ under IR and HR (16 and 13.5, respectively). Again, differences among species were very pronounced, especially in the LR treatment (invasive species: $17-42 \mathrm{mg} \mathrm{g}^{-1}(\mathrm{~N}), 0.8-1.8 \mathrm{mg} \mathrm{g}^{-1}(\mathrm{P})$; native species: 9-26 $\mathrm{mg} \mathrm{g}^{-1}(\mathrm{~N}), 0.9-1.1 \mathrm{mg} \mathrm{g}^{-1}(\mathrm{P})$ ).

Adding nutrients led to significant increases in the concentrations of both $\mathrm{N}$ and $\mathrm{P}$ in the leaves 


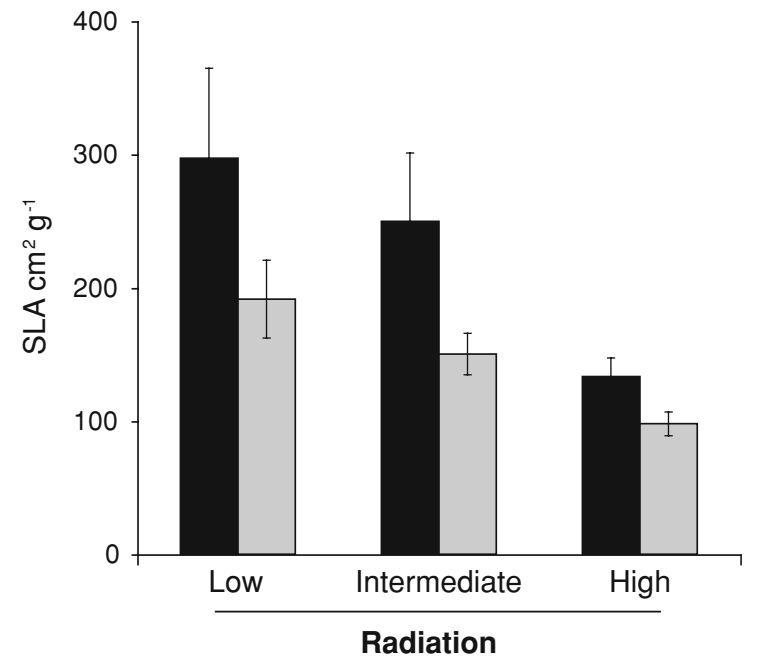

Fig. 3 Specific leaf area (SLA) of invasive (black bars) and native (grey bars) species (mean $\pm \mathrm{SE}$, based on species means). Plants growing under three light levels with no fertilizer added. See text for further information

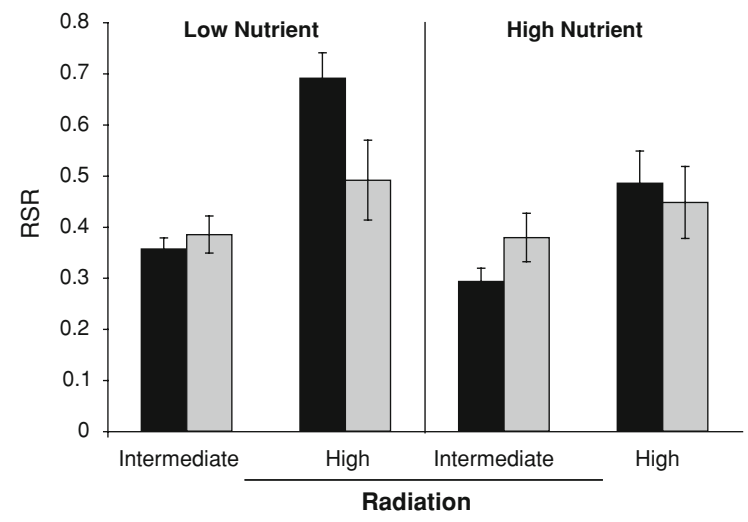

Fig. 4 Root:shoot ratio (RSR) of invasive (black bars) and native (grey bars) tree species (mean $\pm \mathrm{SE}$, based on species means). Data for plants growing under two light and two nutrient levels. See text for further information

(Table 3, Fig. 5), and the N:P ratios in these plants were also $15-18 \%$ higher than in the low nutrient treatment. There was also a significant interaction with status group, as invasive species profited more from adding nutrients (species status $\times$ nutrients). However, this species group effect occurred almost exclusively under HR, leading to a significant threeway interaction (status $\times$ light $\times$ nutrients, $\mathrm{N}$ : $\mathrm{SS}=1.3, \quad F=10.9, \quad P=0.001 ; \quad \mathrm{P}: \quad \mathrm{SS}=0.1$, $F=12.5, P<0.001)$. Under HR conditions, the invasive species increased their leaf $\mathrm{N}$ and $\mathrm{P}$ contents in response to nutrient addition by c. $75 \%$ and $50 \%$, respectively, while the corresponding increases in the native species were much lower (c. $25 \%$ and $10 \%$, respectively; Fig. 5).

\section{Discussion}

We found that seedling growth was higher under both high light and high nutrient conditions than with low levels of these resources. Since we chose these resource levels to be typical of the ranges occurring in forest environments in the Seychelles, these results suggest that juvenile tree growth in forests is strongly limited by both light and nutrients. In addition, there were changes in biomass allocation towards plant organs that acquire whichever resource was more limiting. Thus, with an increase in light there was an increase in RSR and a decrease in LAR, while the reverse trends were found when nutrients were added. Although it is not possible from this experiment to determine which nutrients are most critical, the finding that both leaf $\mathrm{N}$ and $\mathrm{P}$ contents increased after fertilisation with an N-P-K fertilizer suggests that both nutrients (and possibly also $\mathrm{K}$, compare Kueffer et al. 2008) limit the growth of tree seedlings. Further support for this suggestion is provided by the leaf $\mathrm{N}: \mathrm{P}$ values, which are in the range that would be expected with co-limitation (i.e. c. 15, Koerselman and Meuleman 1996; Güsewell and Koerselman 2002).

Compared with their native counterparts, invasive species included more species with particularly high seedling growth rates (RGR), and they had generally higher SLA and higher leaf nutrient contents. They also exhibited greater plasticity in biomass and nutrient allocation (i.e., greater plasticity in LAR, RSR, leaf nutrient contents) in response to resource availability. This was reflected in an increased differentiation between the two groups under high resource conditions (Figs. 2b, 4, and 5). Although these patterns fit with current generalizations about what makes some plant species invasive (Daehler 2003; Niinemets et al. 2003; Richards et al. 2006; Richardson and Pysek 2006), the differences in mean values between the two species groups were mainly small compared with the variation within groups. 

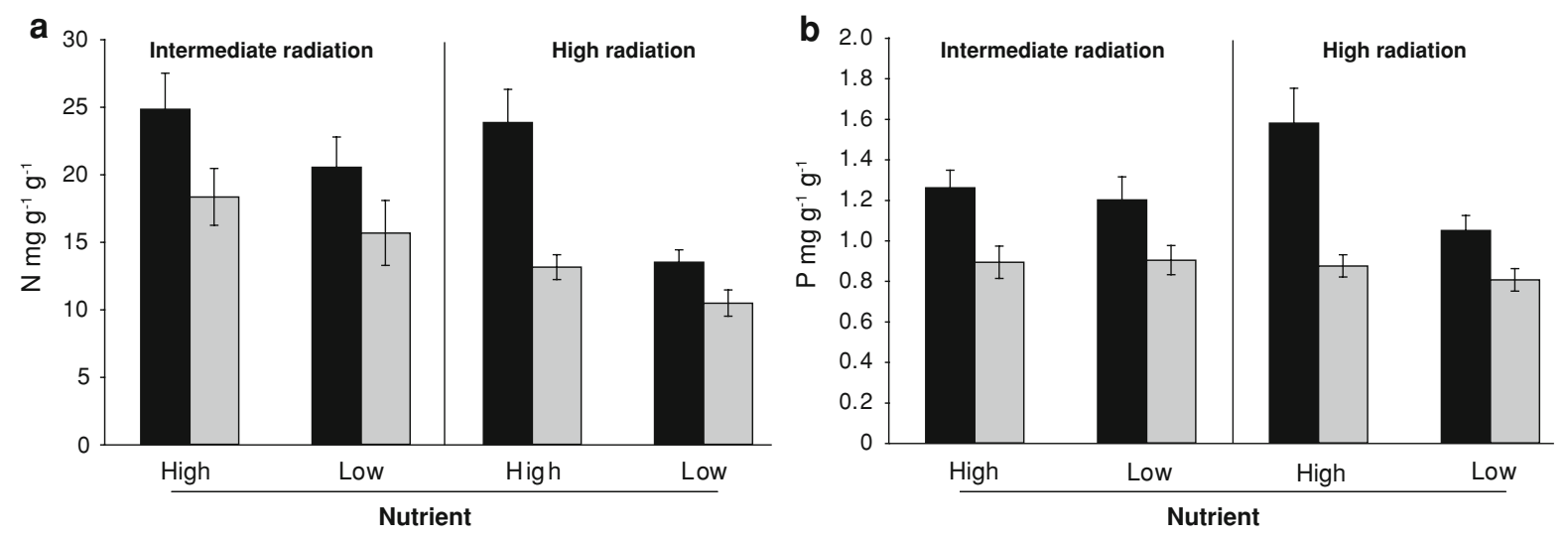

Fig. 5 Leaf nutrient contents of invasive (black bars) and native (grey bars) tree species (mean \pm SE, based on species means). Data for plants growing under two light and two nutrient levels. See text for further information. a Nitrogen (N). b Phosphorus (P)

Higher variability of growth characteristics among invasive species

There were interesting patterns of variation in plant traits (SLA and leaf nutrient contents, Fig. 6) and growth rates (RGR, data not shown) within both groups of species. Two invasive species, A. macrophylla and T. pallida, produced leaves with notably high SLA across all light and nutrient treatments (Fig. 6), and their relative growth rates (RGR) under high light availability were $25-50 \%$ higher than those of most of the other species. In contrast, SLA and leaf nutrient contents of the other four invasive species were either similar to those of the native species under all treatments (Psidium cattleianum and $S$. jambos), or under all but the high light/high nutrient treatment (C. verum and $S$. koetjape; Fig. 6).

These results, together with data on spatial distributions of these species in the field (Fleischmann 1997; Kueffer and Vos 2004), indicate that the species invading closed forest on nutrient-poor soils in the Seychelles have traits associated with stress
Fig. 6 Nitrogen leaf content $(\mathrm{N})$ versus specific leaf area (SLA) for plants growing under two light and two nutrient levels. Invasive species are indicated with filled symbols: triangles for the two fast-growing

(A. macrophylla \&

T. pallida) and diamonds for the four stress-tolerant invaders. The native species are shown in open symbols: squares for the two indigenous species (A. theiformis \& C. bibracteatum) and circles for the four endemic species

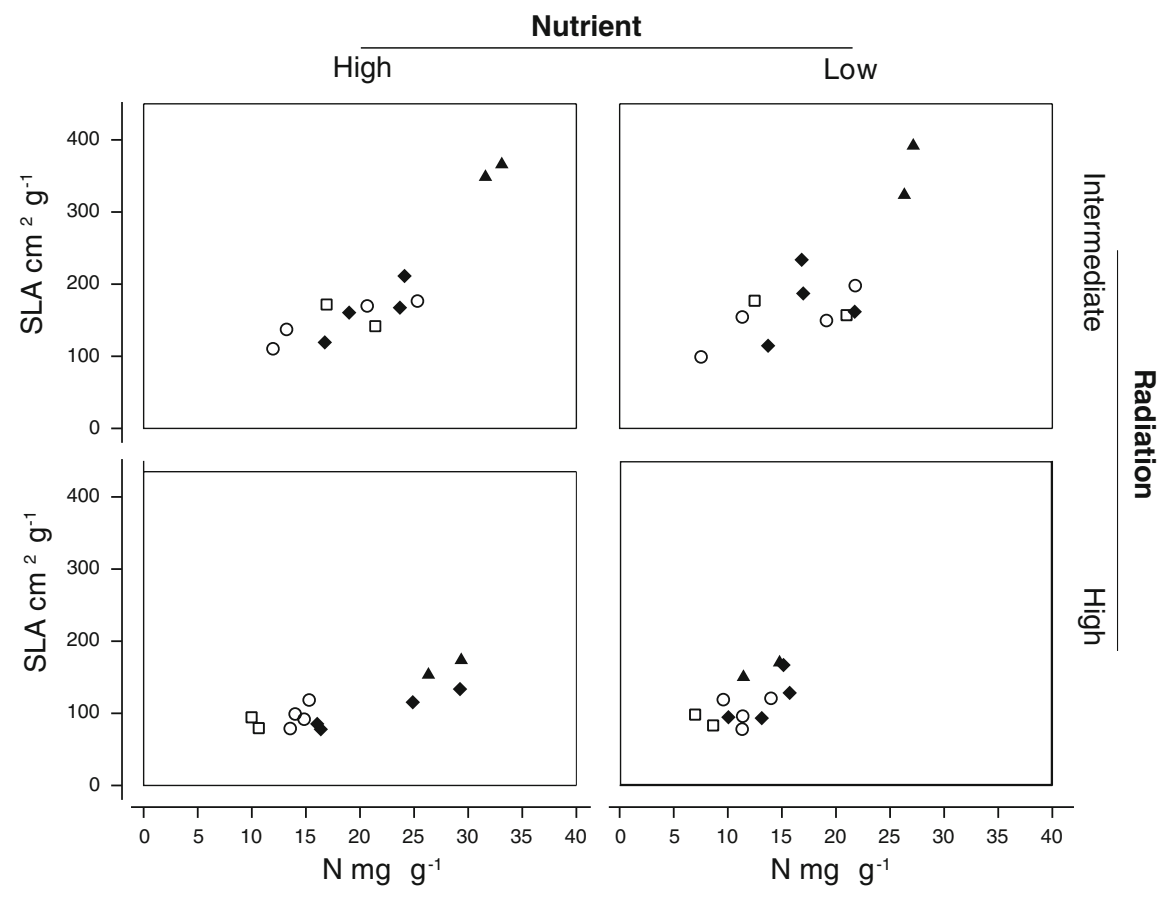


tolerance, while the more typical 'fast-growing' invaders are restricted to more nutrient-rich, disturbed sites, especially in the lowlands (with the notable exception of A. macrophylla, see below). Support for this conclusion comes by comparing $P$. cattleianum with a related alien species, $P$. guajava, that is invasive in many subtropical and tropical countries but in the Seychelles has only become naturalised in a few coastal habitats. When grown in an experimental setup similar to that described here (Schumacher, unpublished), P. guajava had a higher SLA (data not shown) and RGR than $P$. cattleianum under high light, while under low light $P$. guajava had the same $\mathrm{RGR}_{\mathrm{DW}}$ as $P$. cattleianum but a lower $\mathrm{RGR}_{\mathrm{LA}}$ (Fig. 7). Thus, P. guajavawhich is not invasive in Seychelles-has traits similar to those of many other invasive species in the tropics, while $P$. cattleianum - which is invasive-has characteristics more typical of a stress tolerator.

Among the native species, within-group variation was smaller, and even the two non-endemic species, Aphloia theiformis and Canthium bibracteatum, did not differ from endemic species in their leaf traits (Fig. 6). It is interesting, however, that these species-which typically occur in disturbed environments-had higher RGR's than the other native species. It has been hypothesised that one of the reasons why oceanic islands are especially prone to invasion is that the native plants tend to exhibit relatively low environmental specialisation and a correspondingly low competitiveness (see Denslow 2003). Our study indicates that the invasive flora may be better able to exploit high resource conditions than the native flora, but more studies are needed in which the growth characteristics of a wider array of island plants are screened in order to test this hypothesis.
Fast-growing invasive species

The two fast-growing invasive species, A. macrophylla and T. pallida, showed the ecological characteristics expected of a successful plant invader (e.g. Baker 1974): in the experiment they grew strongly under high resource availabilities, and in the field they are found mainly (A. macrophylla) or exclusively (T. pallida) in highly disturbed environments. Indeed, these species grew so fast in the experiment that towards the end their growth may have been restricted by the size of the pots, especially in the high resource treatments. However, this effect would not have altered the overall ranking of these species.

Surprisingly, A. macrophylla also survived in the low light treatment and was the fastest growing species under intermediate and low light. One explanation for its relatively high shade tolerance is a high phenotypic plasticity: A. macrophylla adjusted RSR and SLA by a factor of three from low to high resource conditions, and consequently had one of the lowest root:shoot ratios and highest SLAs under low light. Furthermore, the leaf $\mathrm{N}$ content of A. macrophylla under low light was about twice that of any other species (data not shown), suggesting that it has a high ability to take up nutrients from infertile soils (compare Kueffer 2006). However, despite this evidence for high phenotypic plasticity, seedlings of A. macrophylla are not found in the least disturbed forests in Seychelles, in contrast to many endemic species and stress-tolerant invasive species such as P. cattleianum.

\section{Stress-tolerant invasive species}

The four stress-tolerant alien species in our experiment included the three alien trees $C$. verum, $P$. cattleianum
Fig. 7 Relative growth rates of dry weight $\left(\mathrm{RGR}_{\mathrm{DW}}, \mathbf{a}\right)$ and of leaf area $\left(\mathrm{RGR}_{\mathrm{LA}}, \mathbf{b}\right)$ of the invasive Psidium cattleianum and the non-invasive alien Psidium guajava under low, intermediate and high radiation
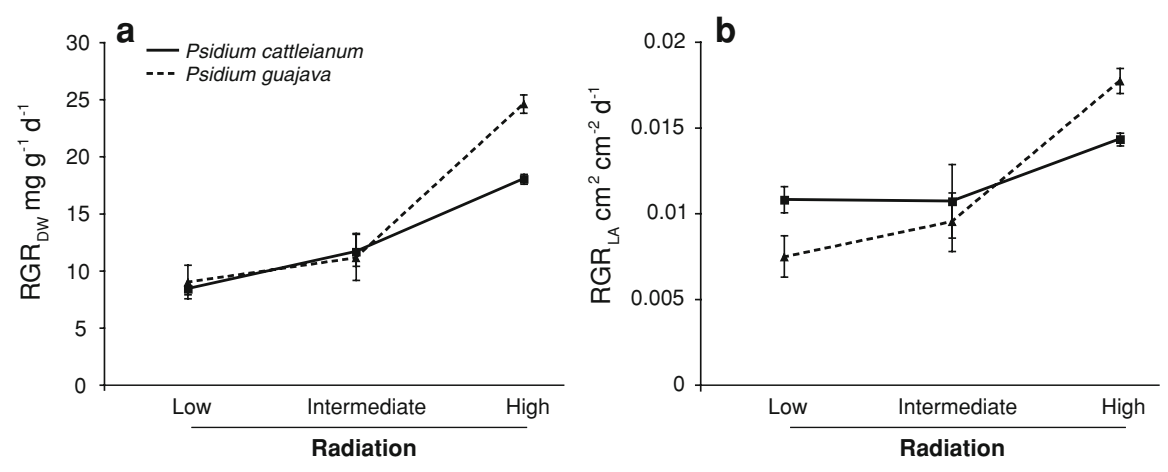
and $S$. jambos that invade relatively undisturbed mountain forests in the Seychelles. Indeed, two of them (P. cattleianum, S. jambos) can regenerate so vigorously in closed forest that they sometimes prevent regeneration of native species (Kueffer and Vos 2004; Kueffer 2006), while C. verum has also a strong but more complex impact on forest regeneration (Kueffer et al. 2007). All three species are considered problematic invaders across the whole tropics (Weber 2003). In contrast, the fourth species, S. koetjape, is restricted to the understorey of plantation forests, where it forms a dense sapling layer. Its restricted distribution can probably be explained by the fact that its large fruits are not readily dispersed.

Although the stress-tolerant invasive species tended to respond to changes in resource availability more plastically than native species, other traits are probably more important in enabling these species to dominate the understory. These traits include vegetative reproduction (P. cattleianum), large seeds producing large seedlings (S. jambos, S. koetjape), and abundant production of bird-dispersed seeds (C. verum) (Kueffer 2006; Kueffer et al. 2007). On a landscape scale, the fact that these trees grow under a wide range of resource conditions may also contribute to their success by enhancing propagule pressure. Some of the species invasive in closed forest, such as $C$. verum and $P$. cattleianum, are also common on many granitic rock outcrops. These plants produce large seed crops that may subsequently be dispersed to the surrounding forests by birds (compare Kueffer and Vos 2004; Kueffer 2006).

\section{A finer picture of plant invasiveness}

The successful plant invaders of closed-canopy secondary forests on nutrient-poor soils in the Seychelles (and probably also in many other tropical areas) appear to be of two types: stress-tolerant invaders (e.g., P. cattleianum and S. jambos) and fast-growing invaders with particular adaptations to nutrient-poor soils (e.g., A. macrophylla). In contrast, the more typical, fast-growing alien species are restricted to the relatively nutrient-rich lowland plateau (e.g., P. guajava and T. pallida). Such distinct specialisations among invaders could also explain why no clear trends have been found in the ecological traits of invasive species in other nutrientpoor areas (e.g., Bellingham et al. 2004).
This conclusion has important implications for invasion biology in general. It becomes increasingly clear that, rather than being 'super-weeds' that outcompete native species under all conditions, most invasive species only prevail under a certain set of habitat conditions. Thus, different invasive species may exhibit more extreme traits than native species at opposite ends of the ecological spectrum (Crawley et al. 1996; Richardson and Pysek 2006). Rather than reflecting general features of all invasive species, therefore, the traits that have been associated with successful invaders through broad comparisons of invasive and native floras could merely reflect the fact that invasions in disturbed habitats are more common (Maskell et al. 2006) and have received more attention. However, as in the Seychelles, invasions also happen in undisturbed and resource-poor ecosystems (e.g. Stohlgren et al. 1999; Dietz and Edwards 2006; Martin and Marks 2006, and references therein), where they often have a negative impact on biodiversity and ecosystem functioning. Understanding why these invasions occur, therefore, is not only a matter of scientific interest (Dietz and Edwards 2006) but of practical importance for management.

Acknowledgements We thank the Seychelles Ministry of Environment and Natural Resources for their support with conducting the experiment, and particularly the staff of the Sans Souci forestry station for their assistance with the common garden experiment. At the Institute of Integrative Biology (ETH Zurich), Sabine Güsewell provided statistical advice, and Rose Trachsler and Marilyn Gaschen assisted with the chemical analyses of leaf and soil samples.All experiments were performed after review by the local Ministry of Environment and complied with the current laws of the Seychelles. Funding was provided by a research grant from the Swiss Federal Institute of Technology (ETH Zurich) to HD.

\section{References}

Alpert P, Bone E, Holzapfel C (2000) Invasiveness, invasibility and the role of environmental stress in the spread of nonnative plants. Perspect Plant Ecol Evol Syst 3:52-66. doi: 10.1078/1433-8319-00004

Baker HG (1974) The evolution of weeds. Annu Rev Ecol Syst 5:1-24. doi:10.1146/annurev.es.05.110174.000245

Baruch Z, Goldstein G (1999) Leaf construction cost, nutrient concentration, and net $\mathrm{CO}_{2}$ assimilation of native and invasive species in Hawaii. Oecologia 121:183-192. doi: 10.1007/s004420050920

Baruch Z, Pattison RR, Goldstein G (2000) Responses to light and water availability of four invasive Melastomataceae in the Hawaiian islands. Int J Plant Sci 161:107-118. doi: $10.1086 / 314233$ 
Bellingham PJ, Duncan RP, Lee WG, Buxton RP (2004) Seedling growth rate and survival do not predict invasiveness in naturalized woody plants in New Zealand. Oikos 106:308-316. doi:10.1111/j.0030-1299.2004. 13171.x

Braithwaite CJR (1984) Geology of the Seychelles. In: Stoddart DR (ed) Biogeography and Ecology of the Seychelles Islands, pp 17-38, DR W. Junk Publishers, The Hague, Boston, Lancaster

Burke A (2003) Inselbergs in a changing world - global trends. Divers Distrib 9:375-383. doi:10.1046/j.1472-4642.2003. 00035.x

Cavieres LA, Quiroz CL, Molina-Montenegro MA, Munoz AA, Pauchard A (2005) Nurse effect of the native cushion plant Azorella monantha on the invasive non-native Taraxacum officinale in the high-Andes of central Chile. Perspect Plant Ecol Evol Syst 7:217-226. doi:10.1016/ j.ppees.2005.09.002

Crawley MJ, Harvey PH, Purvis A (1996) Comparative ecology of the native and alien flora of the British Isles. Philos Trans R Soc Lond B Biol Sci 351:121-159. doi:10.1098/ rstb.1996.0108

Daehler CC (2003) Performance comparisons of co-occurring native and alien invasive plants: implications for conservation and restoration. Annu Rev Ecol Syst 34:183-211. doi:10.1146/annurev.ecolsys.34.011802.132403

Davis MA, Grime JP, Thompson K (2000) Fluctuating resources in plant communities: a general theory of invasibility. J Ecol 88:528-534. doi:10.1046/j.1365-2745. 2000.00473.x

Denslow JS (2003) Weeds in paradise: thoughts on the invasibility of tropical islands. Ann Mo Bot Gard 90:119-127. doi: $10.2307 / 3298531$

Dietz H, Edwards PJ (2006) Recognition that causal processes change during plant invasion helps explain conflicts in evidence. Ecology 87:1359-1367. doi:10.1890/0012-9658 (2006)87[1359:RTCPCD]2.0.CO;2

Dietz H, Steinlein T (1996) Determination of plant species cover by means of image analysis. J Veg Sci 7:131-136. doi: $10.2307 / 3236426$

Dukes JS, Mooney HA (1999) Does global change increase the success of biological invaders? Trends Ecol Evol 14:135139. doi:10.1016/S0169-5347(98)01554-7

Ehrenfeld JG (2003) Effects of exotic plant invasions on soil nutrient cycling processes. Ecosystems (N Y, Print) 6:503-523. doi:10.1007/s10021-002-0151-3

Fine PVA (2002) The invasibility of tropical forests by exotic plants. J Trop Ecol 18:687-705

Fleischmann K (1997) Invasion of alien woody plants on the islands of Mahé and Silhouette, Seychelles. J Veg Sci 8:5-12. doi:10.2307/3237236

Friedmann F (1994) Flore des Seychelles. Orstom, Paris

Gibson DJ (2002) Methods in comparative plant population ecology. Oxford University Press, Oxford, New York

Grotkopp E, Rejmanek M, Rost TL (2002) Toward a causal explanation of plant invasiveness: seedling growth and life-history strategies of 29 Pine (Pinus) species. Am Nat 159:396-419. doi:10.1086/338995

Güsewell S, Koerselman W (2002) Variation in nitrogen and phosphorus concentrations of wetland plants. Perspect
Plant Ecol Evol Syst 5:37-61. doi:10.1078/1433-83190000022

Huenneke LF, Vitousek PM (1990) Seedling and clonal recruitment of the invasive tree Psidium cattleianum: implications for management of native Hawaiian forests. Biol Conserv 53:199-211. doi:10.1016/0006-3207(90) 90086-5

Koerselman W, Meuleman AFM (1996) The vegetation N:P ratio: a new tool to detect the nature of nutrient limitation. J Appl Ecol 33:1441-1450. doi:10.2307/2404783

Kolar CS, Lodge TS (2001) Progress in invasion biology: predicting invaders. Trends Ecol Evol 16:199-204. doi: 10.1016/S0169-5347(01)02101-2

Kueffer C (2006) Impacts of woody invasive species on tropical forests of the Seychelles, Department of Environmental Sciences, Diss. ETH No. 16602, ETH Zurich, Zurich, pp. 160

Kueffer C, Vos P (2004) Case studies on the status of invasive woody plant species in the Western Indian ocean: 5. Seychelles. Forestry department. Food and Agriculture Organization of the United Nations, Rome, Italy

Kueffer C, Klingler G, Zirfass K, Schumacher E, Edwards P, Güsewell S (2008) Invasive trees show only weak potential to impact nutrient dynamics in phosphorus-poor tropical forests in the Seychelles. Funct Ecol 22:359-366

Kueffer C, Schumacher E, Fleischmann K, Edwards PJ, Dietz $\mathrm{H}$ (2007) Strong belowground competition shapes tree regeneration in invasive Cinnamomum verum forests. J Ecol 95:273-282. doi:10.1111/j.1365-2745.2007.01213.x

Martin PH, Marks PL (2006) Intact forests provide only weak resistance to a shade-tolerant invasive Norway maple (Acer platanoides L.). J Ecol 94:1070-1079. doi: 10.1111/j.1365-2745.2006.01159.x

Maskell LC, Firbank LG, Thompson K, Bullock JM, Smart SM (2006) Interactions between non-native plant species and the floristic composition of common habitats. J Ecol 94:1052-1060. doi:10.1111/j.1365-2745.2006.01172.x

Millennium Ecosystem Assessment (2005) Ecosystems and human well-being: biodiversity synthesis. World Resources Institute, Washington, DC

Niinemets U, Valladares F, Ceulemans R (2003) Leaf-level phenotypic variability and plasticity of invasive Rhododendron ponticum and non-invasive Ilex aquifolium co-occurring at two contrasting European sites. Plant Cell Environ 26:941-956. doi:10.1046/j.1365-3040.2003. 01027.x

Pimentel D, Zuniga R, Morrison D (2005) Update on the environmental and economic costs associated with alieninvasive species in the United States. Ecol Econ 52:273288. doi:10.1016/j.ecolecon.2004.07.013

Richards AJ, Bossdorf O, Muth NZ, Gurevitch J, Pigliucci M (2006) Jack of all trades, master of some? On the role of phenotypic plasticity in plant invasions. Ecol Lett 9:981993. doi:10.1111/j.1461-0248.2006.00950.x

Richardson DM, Pysek P (2006) Plant invasions: merging the concepts of species invasiveness and community invasibility. Prog Phys Geogr 30:409-431. doi:10.1191/0309133306pp 490pr

Schmitt L, Riviere JN (2002) Comparative life-history traits of two Syzygium species (Myrtaceae): one invasive alien in 
La Réunion, the other native. Acta Bot Gallica 149: 457-466

Stoddart DR (ed) (1984) Biogeography and ecology of the Seychelles islands. DR W. Junk Publishers, The Hague, Boston, Lancaster

Stohlgren TJ, Binkley D, Chong GW, Kalkhan MA, Schell LD, Bull KA, Otskul Y, Newman G, Bashkin M, Son Y (1999) Exotic plant species invade hot spots of native plant diversity. Ecol Monogr 69:25-46

Veneklaas EJ, Poorter L (1998) Growth and carbon partitioning of tropical tree seedlings in contrasting light environments. In: Lambers $\mathrm{H}$, Poorter $\mathrm{H}$, Van Vuuren MMI (eds) Inherent variation in plant growth: physiological mechanisms and ecological consequences. Backhuys, Leiden

Vitousek PM (1990) Biological invasions and ecosystem processes: towards an integration of population biology and ecosystem studies. Oikos 57:7-13. doi:10.2307/3565731

Vitousek PM (2004) Nutrient cycling and limitation. Hawai'i as a model system. Princeton University Press, Princeton

Weber E (2003) Invasive plant species of the world. A reference guide to environmental weeds. CABI Publishing, Oxon, UK \& Cambridge, USA

Williamson M (1996) Biological invasions. Chapman \& Hall, London, New York, Tokyo 